\title{
ARTICLE OPEN \\ Little evidence of reduced global tropical cyclone activity following recent volcanic eruptions
}

\author{
Suzana J. Camargo (iD ${ }^{1}$ and Lorenzo M. Polvani $\mathbb{i D}^{2}$
}

The impact of volcanic aerosols on recent global tropical cyclone (TC) activity is examined in observations, reanalysis, and models (the Coupled Model Intercomparison Project phase 5 - CMIP5 multi-model, and one single model large ensemble). In observations, we find a reduction of TC activity only in the North Atlantic following the last three strong volcanic eruptions; that signal, however, cannot be clearly attributed to volcanoes, as all three eruptions were simultaneous with El Niño events. In reanalyses, we find no robust impact of volcanic eruptions on potential intensity $(\mathrm{PI})$ and genesis indices. In models, we find a reduction in $\mathrm{PI}$ after volcanic eruptions in the historical simulations, but this effect is significantly reduced when differences between the model environment and observations are accounted for. Morever, the CMIP5 multi-model historical ensemble shows no effect of volcanic eruptions on a TC genesis index. Finally, there is no robust and consistent reduction in recent TC activity following recent volcanic eruptions in a large set of synthetic TCs downscaled from these simulations. Taken together, these results show that in recent eruptions volcanic aerosols did not reduce global TC activity.

npj Climate and Atmospheric Science (2019)2:14; https://doi.org/10.1038/s41612-019-0070-z

\section{INTRODUCTION}

Volcanic eruptions inject sulfur gases into the stratosphere, which convert to sulfate aerosols. The radiative and chemical effects of such stratospheric aerosols can then impact the climate system. Among the well known responses to volcanic eruptions are the cooling of surface air by the scattering of solar radiation back to space, and the warming of the lower stratosphere by the absorption of both solar and terrestrial radiation. ${ }^{1}$

A question of great interest is whether volcanic eruptions are able to affect tropical cyclone (TC) activity. Volcanic aerosols injected into the stratosphere by volcanic eruptions reflect the incoming solar radiation, causing lower sea surface temperature (SST): this, in turn, might be expected to result in weaker and fewer TCs. Furthermore, TC potential intensity (PI) theory, originally proposed by Emanuel, ${ }^{2}$ states the that TC intensity is directly proportional to SST and inversely proportional to the outflow temperature. Therefore, a cooling of the ocean surface and a warming at the atmosphere at the outflow level, due to volcanic eruptions, might lead to weaker TCs. Since many genesis indices use $\mathrm{Pl}$ as one of their components, ${ }^{3,4}$ warming aloft and cooling at the surface would lead to lower values of these indices and thus a reduction in genesis occurrence.

In fact, a few studies have claimed that a causal link exists between volcanic eruptions and TCs. Early work by Elsner and Kara ${ }^{5}$ suggested an increase in North Atlantic hurricane frequency 3-4 years after major volcanic eruptions. More recently, Evan ${ }^{6}$ reported a reduction in North Atlantic TC activity following the eruptions of El Chichón and Pinatubo, and suggested that the reduced hurricane activity might have been caused by those eruptions. However, those two eruptions coincided with El NiñoSouthern Oscillation (ENSO) warm events. Since El Niño is well known to reduce North Atlantic TC activity, ${ }^{7}$ one cannot immediately conclude that the observed reduction in that basin was caused by volcanic aerosols.

As for earlier eruptions, Guevara-Murua et al. ${ }^{8}$ analyzed reconstructions of TCs following major volcanic eruptions, and found a consistent reduction of North Atlantic TC activity in the 3 years following the eruptions. In addition to the fact that their finding is based on proxy reconstructions and not actual observations, they did not propose a mechanism to explain how high-latitude volcanic eruptions would cause a reduction of North Atlantic TC activity. In addition, Chiacchio et al. ${ }^{9}$ noted a relationship between lower stratospheric temperatures and Atlantic TC frequency, but their finding was statistical, and leaves the causality and the mechanism unclear. Korty et al. ${ }^{10}$ analyzed a Last Millenium model simulation and noticed a reduction in the potential intensity following volcanic eruptions. Using a genesis index to analyze the same simulation, Yan et al. ${ }^{11}$ reported that TC activity appears to be impacted by stratospheric aerosols of volcanic origin in that model, directly (through the radiative forcing) and indirectly (through the El Niño-Southern Oscillation), but without separating these potential pathways.

In this paper, to evaluate the robustness of these claims, we examine the question of whether volcanic aerosols reduced recent global TC activity. Unlike previous work, we here use a comprehensive strategy. First, we address the question with a three-pronged approach and we examine observations, reanalyses, and models. Second, we extend previous work by considering the global TC activity, not just the North Atlantic basin. If volcanic eruptions have a robust direct impact on reducing TC activity, a clear signal should be present globally, as stratospheric aerosols rapidly cover the entire tropical belt in the case of low-latitude eruptions, such as Agung, El Chichón and Pinatubo. Therefore, the key question is whether a robust

\footnotetext{
'Lamont-Doherty Earth Observatory, Columbia University, Palisades, NY, USA and ${ }^{2}$ Department of Earth and Environmental Sciences and Department of Applied Physics and Applied Mathematics, Columbia University, New York, NY, USA

Correspondence: Suzana J. Camargo (suzana@Ideo.columbia.edu)
}

Received: 21 December 2018 Accepted: 1 May 2019

Published online: 17 May 2019 
reduction of global TC activity exists following volcanic eruptions. As there are very few large volcanic eruptions during the period of reliable historical TC data, the use of models is crucial to answering that question. As described in detail below, our comprehensive strategy reveals the lack of a robust reduction of global TC activity after recent volcanic eruptions, and this finding is consistent across observations, reanalyses, and models.

\section{RESULTS}

Observations

We start by asking whether there is any evidence of a global TC response to volcanic eruptions in observations. In Fig. 1 we present five key TC metrics - NTC (number of tropical cyclones), NTC15 (NTC categories 1-5), NTC35 (NTC categories 3-5), ACE (accumulated cyclone energy), and LMI (lifetime maximum intensity) - and contrast the first season following strong volcanic eruptions (colored marks) to the climatological distributions (black box plots). The three large volcanic eruptions have occurred since 1950 are Agung (May 1963), El Chichón (April 1982), and Pinatubo (June 1991). Panels in the left column show the northern hemisphere $(\mathrm{NH})$ and the southern hemisphere $(\mathrm{SH})$, and those in the right column show three $\mathrm{NH}$ individual basins. The climatological distributions are defined for the months of January-December (NH), July-June (SH). In the case of Pinatubo, the TC seasons are January-December 1991 for the $\mathrm{NH}$, and July 1991-June 1992 for the SH. Agung is not shown in the SH, due to (a) NTC

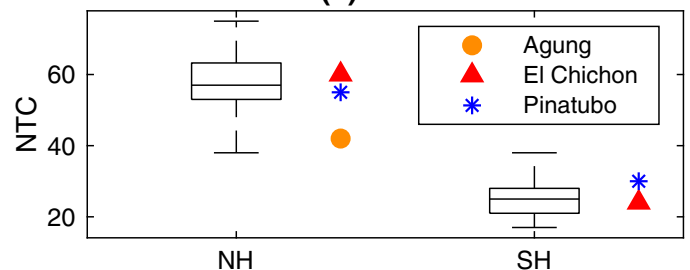

(c) TCs cat. 1-5

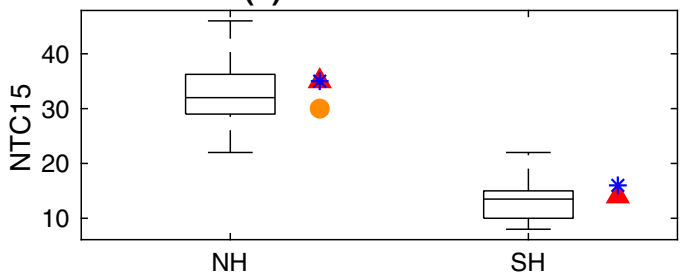

(e) TCs cat. 3-5

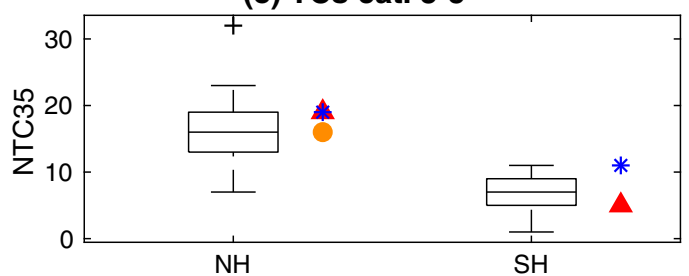

(g) ACE

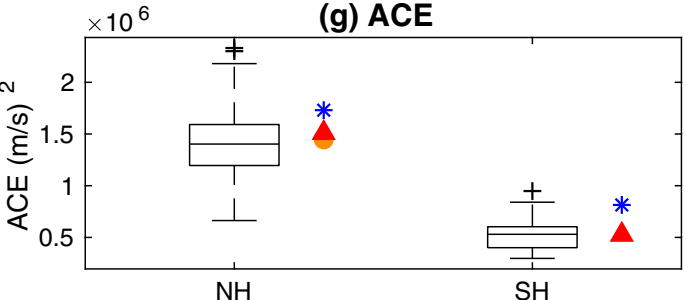

(i) LMI

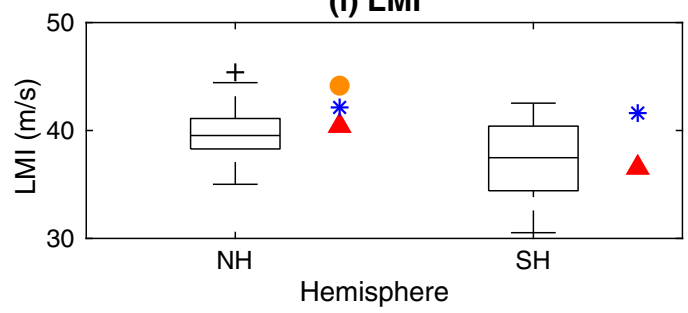

(b) NTC

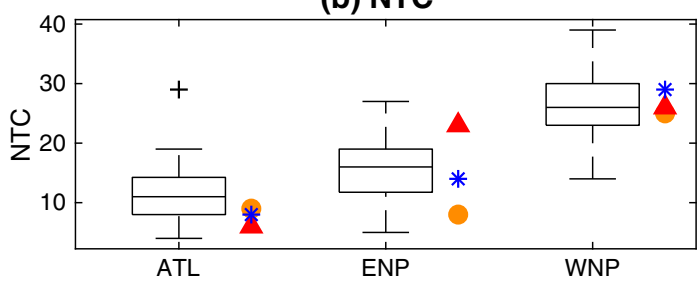

(d) TCs cat. 1-5

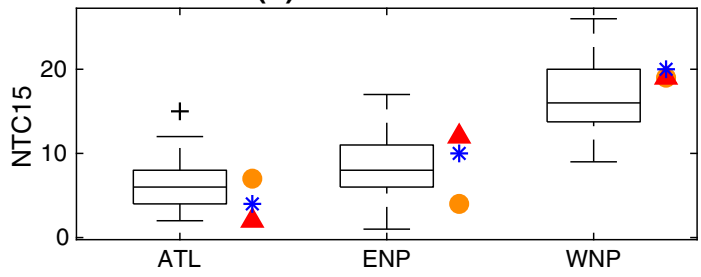

(f) TCs cat. 3-5

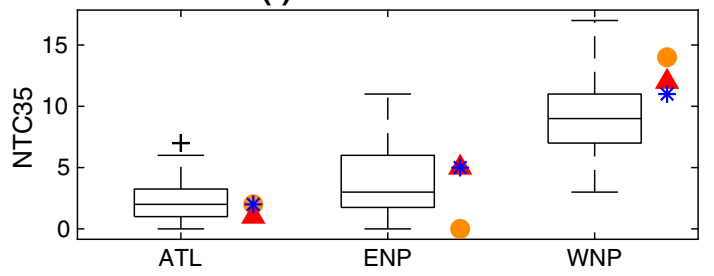

(h) ACE

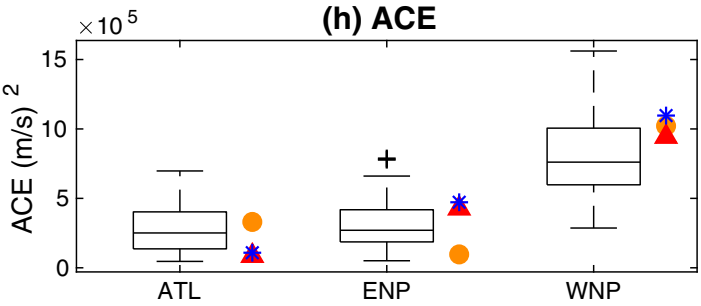

(j) LMI

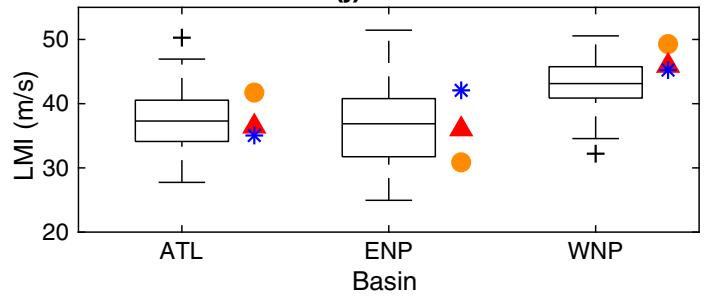

Fig. 1 The box plots (25th to 75th percentiles, central marks indicate the median) show the climatological distribution of NTC $\mathbf{a}$ and $\mathbf{b}$, NTC15 c and $\mathbf{d}$, NTC35 e and f, ACE $\mathbf{g}$ and $\mathbf{h}$, and LMI $\mathbf{i}$ and $\mathbf{j}$. NTC, NTC15, and NTC35 are counts, ACE is in (m/s) ${ }^{2}$ and LMI is in $\left.\mathrm{m} / \mathrm{s}\right)$. The whiskers show the range of the most extreme points not considered outliers, which are marked using + . Colored symbols show the values of these quantities for the first TC season after the volcanoes eruptions. Values for the NH and SH are shown in the left panels, the NH basins: Atlantic (ATL), eastern North Pacific (ENP), and western North Pacific (WNP) in the right panels 


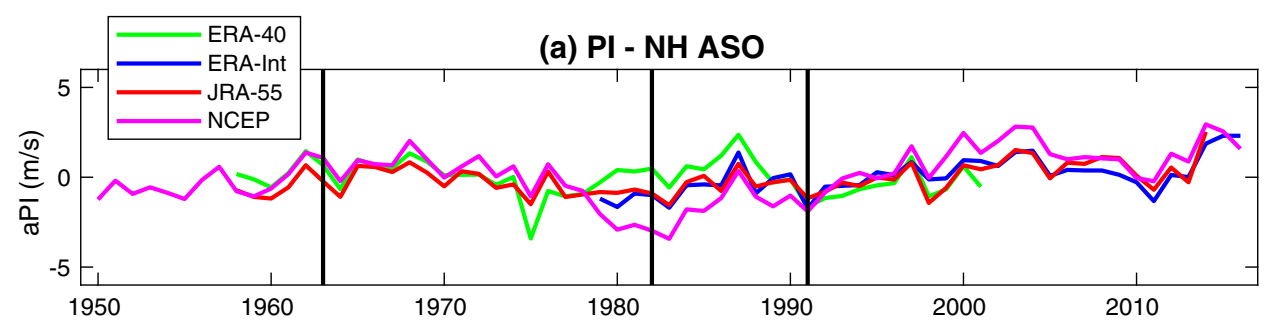

(b) PI - SH JFM

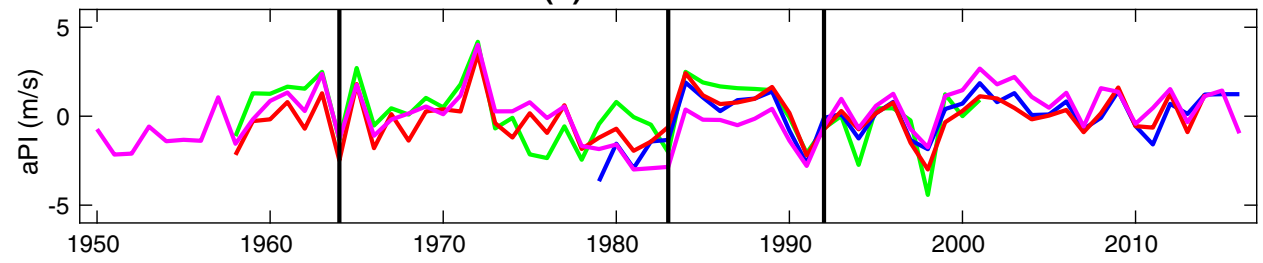

(c) TCGI - NH ASO

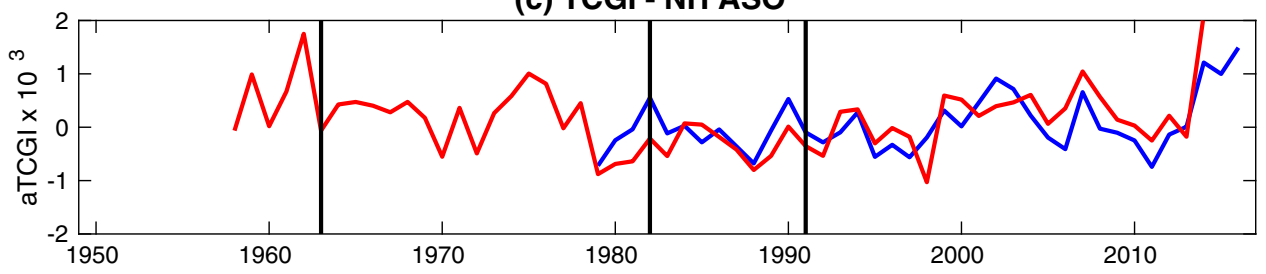

(d) TCGI - SH JFM

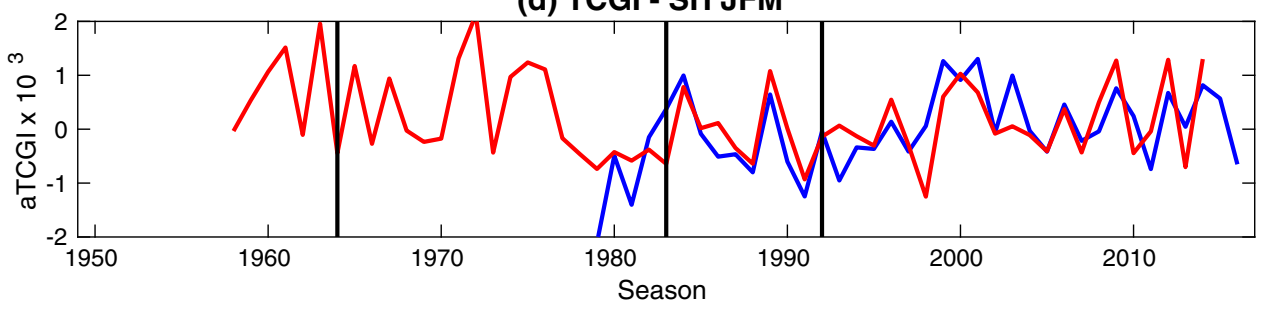

Fig. 2 Time-series of PI anomalies in reanalysis: ERA-40 (green), ERA-Interim (blue), JRA-55 (red), and NCEP (pink) for the a NH in ASO and b SH in JFM. The TCGI ${ }^{15}$ is shown in panels $\mathbf{c}$ and $\mathbf{d}$. The TCGl anomalies were multiplied by $10^{3}$. PI is given in $\mathrm{m} / \mathrm{s}$, TCGI in TC counts. The first TC season in each hemisphere after large volcanic eruptions are marked in black

observed TC data quality issues. Supplementary Fig. 1 shows additional metrics (NTS (number of tropical storms) and NTC12 (NTC categories 1-2)) and Supplementary Fig. 2 all metrics for the North Indian Ocean and southern hemisphere basins.

It is clear that there is no coherent reduction TC activity following these volcanic eruptions, across these five simple metrics (Fig. 1). The only NH basin with below-normal NTC after all three volcanoes is the North Atlantic (see also Supplementary Tables 2-4): however, since the NH TC peak seasons (August to October, ASO) coincide with El Niño events (1963/64, 1982/83, 1991/92) and since the Atlantic TC activity is typically belownormal in El Niño years, one cannot unequivocally attribute this reduction to volcanic influence.

One might also be tempted to claim a below-normal TC activity after Agung in the eastern North Pacific: however, the data quality in that basin prior to 1970 s is very poor, with a spurious increasing trend due to missed storms. ${ }^{12}$ And, in any case, the above-normal activity in that basin after the other two eruptions, is also a typical El Niño response. Finally, note that NH ACE is above-normal for all three post-volcanic seasons, due to the high values of ACE in the Western North Pacific in those seasons. The ENSO modulation of TC activity is complex, decreasing TC activity in some basins and increasing in others, ${ }^{13}$ with an overall increase in ACE in EI Niño years globally, due to a dominant signal in the western North Pacific, ${ }^{14}$ a region with $\sim 30 \%$ of the global TC activity. Both the western North Pacific and the South Pacific (Supplementary Fig. 2) show the typical above-normal TC activity in El Niño years following these volcanic eruptions. All in all, from Fig. 1 we conclude that there is no clear reduction in global TC activity following strong volcanic eruptions in observations.

\section{Reanalyses}

Next we turn to reanalyses, and exploit environmental variables in our attempt to bring out a volcanic signal on global TC activity. Given the decrease in SST and increase in stratospheric temperatures following strong volcanic eruptions, one might expect smaller values of $\mathrm{PI}$ in the tropics following the eruptions. However, as shown in Fig. 2a, b there is no evidence of a robust reduction of $\mathrm{PI}$ either in the $\mathrm{NH}$ during the first ASO season nor in the $\mathrm{SH}$ in the first January to March (JFM) season or the individual basins (Supplementary Fig. 3) following the three, large post-1950 eruptions. Furthermore, we find that the pattern of PI anomalies after the Pinatubo eruption (shown in Supplementary Fig. 4) has a clear El Niño signature, in all reanalyses. Thus, we conclude that the anomaly values in the PI time-series are primarily determined by the strength and pattern of the SST anomalies for each El Niño event, and are not a direct volcanic response.

Next, we examine the genesis index, to see whether a decrease in TC activity is captured by that metric. Recall that genesis indices have proven useful in several instances. In particular, they are able to reproduce the modulation of TCs by the ENSO ${ }^{13,15}$ and the 
Madden-Julian Oscillation. ${ }^{16}$ It needs to be kept in mind that PI and the tropical cyclone genesis index (TGCl) are not independent: the thermodynamic environment (defined by PI) is one of the TCGI ingredients, but genesis indices also include dynamical variables (vertical wind shear and vorticity), as well tropospheric humidity. In any case, TCGI shows no coherent reduction following the same three volcanic eruptions (Fig. 2c, d, Supplementary Fig. 5). This result is corroborated by Supplementary Fig. 6, where the time series of another genesis index (genesis potential index - GPI) are shown. As for Pl, the patterns of the TCGI and GPI anomalies (Supplementary Figs 7 and 8) mirror the ENSO anomalies, similar to the composites shown in Figs 6 and 8 of Camargo et al. ${ }^{13}$ We conclude that El Niño is the only clear signal in these reanalysis metrics, and there is no evidence of a volcanic signal.

\section{CMIP5 models - environmental fields}

Given the small number of observed eruptions, one might argue that the volcanic signal in TC activity might be more detectable from a large number of model simulations. To address this, the PI and TCGI for the the Coupled Model Intercomparison Project phase 5 (CMIP5) historical simulations were calculated using 44 (for PI) and 41 (for TCGI) models, respectively (depending on data availability): they are shown in Fig. 3a, b. In addition to the three large volcanic eruptions already mentioned, the CMIP5 simulations include the eruptions of the Krakatau (August 1883) and Santa María (October 1902). ${ }^{17}$ The CMIP5 models have a volcanic forcing much stronger than observed. ${ }^{17}$ Supplementary Fig. 9 shows the anomalies in outgoing shortwave radiation at the top of the atmosphere in the CMIP5 models. Unlike for reanalyses, the models' PI anomalies appear to reduce significantly following large volcanic eruptions, in both hemispheres. This is not surprising, given the PI effective response to tropospheric aerosol forcing, ${ }^{18}$ similarly to the hydrological cycle. ${ }^{19}$ However, the PI reduction is only clearly apparent for a few basins (Supplementary Fig. 10). Furthermore, it is well known that the response of the CMIP5 models to volcanic eruptions is far from realistic. ${ }^{17,20,21}$ Many global climate models systematically overestimate the response to volcanic eruption, with an excessive surface temperature cooling. This overestimate might be due, in part, to sampling issues in observations, as all the large eruptions in the late 20th century coincided with El Niño events, which leads to a global-scale warming counteracting the volcanic cooling. ${ }^{20}$ It has been clearly documented that most CMIP5 models exaggerate the tropical stratospheric warming accompanying volcanic eruptions. $^{17}$

In addition, the genesis index shown in Fig. 3c, $d$ (and in Supplementary Fig. 11 for individual basins) shows no indication of a significant reduction following the five eruptions. The contrasting responses in $\mathrm{PI}$ and TCGI suggest that while there appears to be a thermodynamic response to the volcanic eruptions in the CMIP5 models, there is no dynamical response. The reason for the lack of dynamic response is that there is no

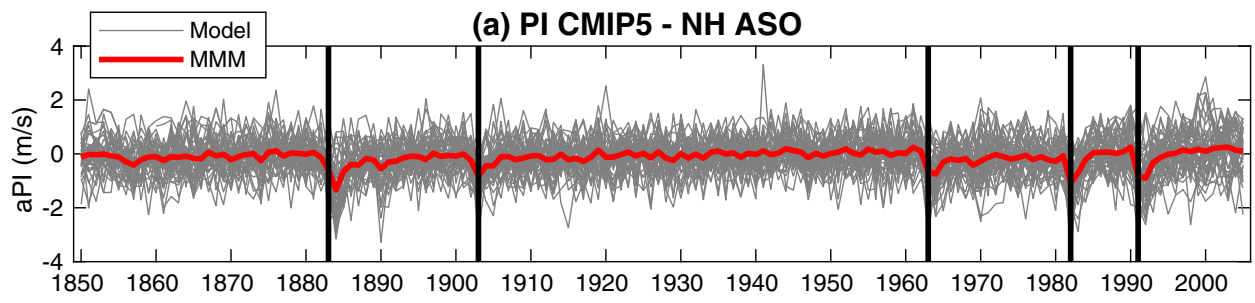

(b) PI CMIP5 - SH JFM

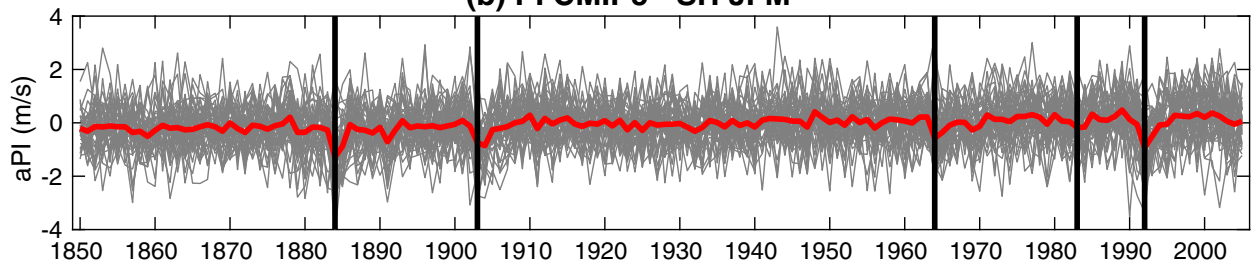

(c) TCGI CMIP5 - NH ASO

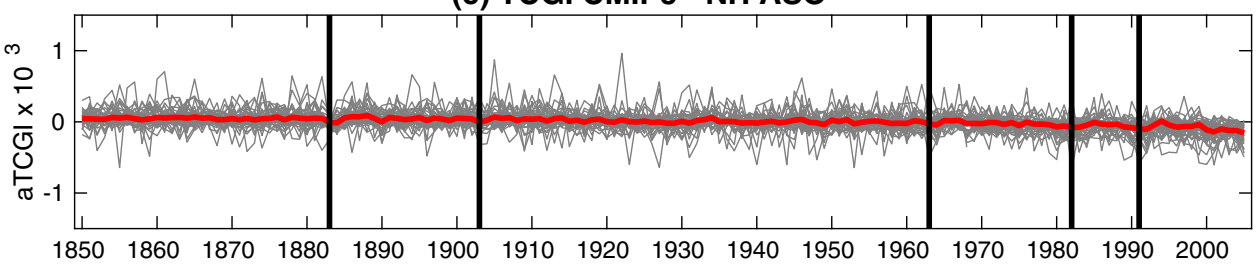

(d) TCGI CMIP5 - SH JFM

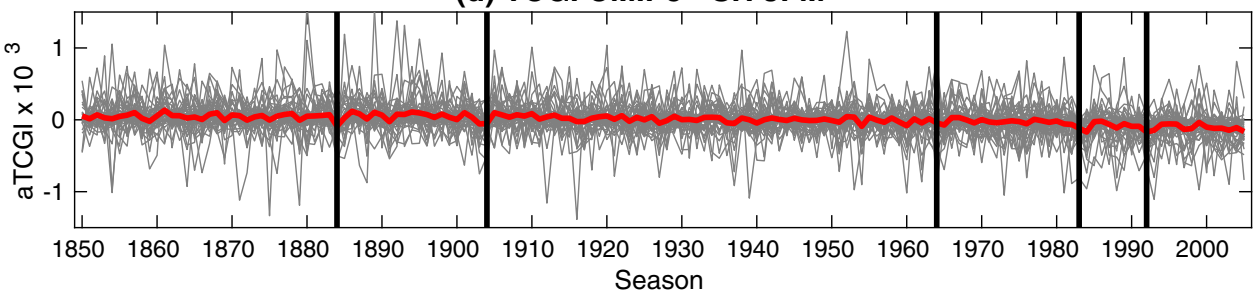

Fig. 3 Time-series of PI $\mathbf{a}$ and $\mathbf{b}$ and TCGI $\mathbf{c}$ and $\mathbf{d}$ anomalies in the the CMIP5 models in for the NH in ASO and SH in JFM. Individual CMIP5 models are shown in the gray lines, the multi-model mean in red. The TCGl anomalies were multiplied by $10^{3}$. PI is given in $\mathrm{m} / \mathrm{s}$, TCGI in TC counts. The first TC season in each hemisphere after large volcanic eruptions are marked in black 
(a) Temperature - CESM-LENS

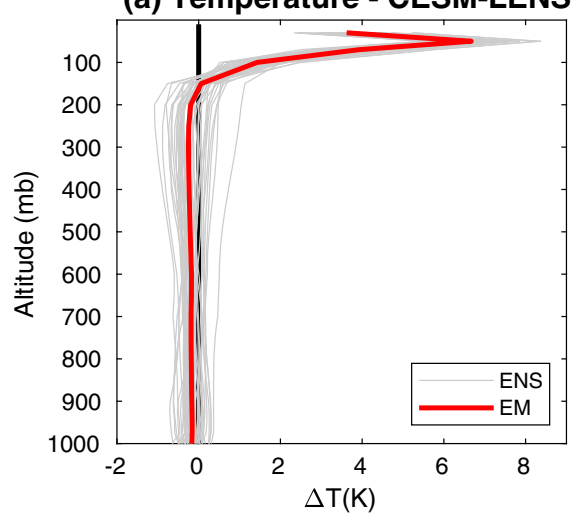

(c) Temperature - Reanalysis

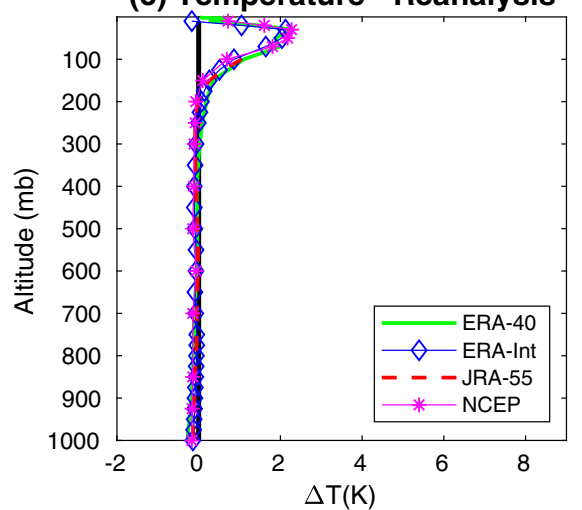

(b) SST - CESM-LENS \& ObS

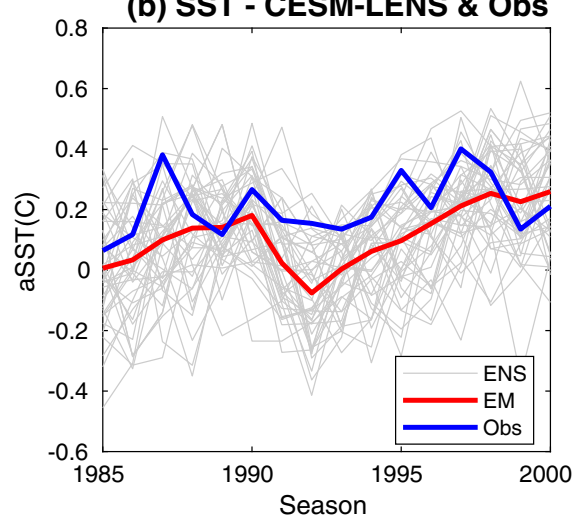

(d) PI - CESM-LENS

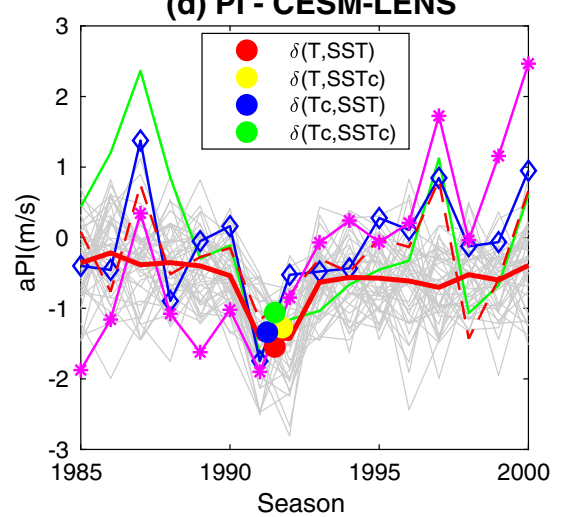

Fig. 4 Difference in tropical northern hemisphere temperature between the ASO seasons after and before Pinatubo eruption in CESM-LENS a and reanalysis c. Time-series of tropical northern hemisphere SST $\mathbf{b}$ and PI anomalies $\mathbf{d}$ in the CESM-LENS simulations. In panels $\mathbf{a}$, $\mathbf{b}$, and $\mathbf{d}$ individual ensemble members are shown in gray, the ensemble mean in red. The observed time-series of SST anomalies are also shown in blue in b. The four reanalysis time-series of PI anomalies (from Fig. 2) are repeated in d. Also shown in $\mathbf{d}$ in the colored marks are the PI anomaly values using bias corrections as described in the text

robust signal in the multi-model mean vertical shear anomaly pattern in the tropics (Supplementary Fig. 12). The lack of consistent changes in the vertical shear across models wipes out the PI response when the TCGI is computed. This is an important result, as it shows a lack of agreement among climate models on a reduction of TCGI in the tropics after volcanic eruptions.

\section{CESM Large Ensemble simulations}

To more precisely quantify the signal-to-noise ratio of the volcanic response, and to better illustrate some common model biases, we next examine the 42 historical simulations of the Community Earth System Model Large Ensemble (CESM-LENS). To the extent that the model ENSO phase is independent of the prescribed volcanic eruption, this analysis should allow us to separate the influence of El Niño and from that of volcanoes. Recall that the modulation of TC activity by ENSO is complex and non-uniform throughout the globe as noted above. Furthermore, El Niño is known to affect stratospheric temperatures, causing cooling in the tropics and warming in the mid-latitudes. ${ }^{22}$ Therefore, if a global reduction in TC activity followed volcanic eruptions, we would expect it to be quite distinct from the typical El Niño response.

Again we compute PI as proxy for TC activity for the CESMLENS: one sees a clear reduction in the ensemble mean following volcanic eruptions in both hemispheres (Supplementary Fig. 13a, b). Note that this reduction is only apparently in a few basins (Supplementary Fig. 14). Examination of the pattern of PI ensemble mean anomaly (Supplementary Fig. 15) for the first TC seasons after each volcanic eruption shows a close resemblance with the SST EI Niño anomalies (Supplementary
Fig. 16): positive anomalies in the equatorial Pacific and negative anomalies in a horse-shoe pattern around it, as well as in most of the North Atlantic. A typical El Niño pattern response for ENSOneutral conditions in this model was already noted. ${ }^{21}$ Unfortunately, as the PI anomaly patterns resemble El Niño teleconnections even when ENSO-neutral conditions are present, a clean separation of ENSO and volcanic responses is impossible.

In addition, we show that the $\mathrm{Pl}$ reduction in this model is unrealistic large, focusing (for simplicity) on the 1991 Pinatubo eruption. Two PI ingredients in the CESM-LENS simulations differ considerably from observations. First, constrasting Fig. 4a, c, one can see that the warming in the lower stratosphere is much larger than observed. Second, one can see in Fig. $4 \mathrm{~b}$ that the ensemble mean SST anomaly is considerably lower than the observed one, owing to the model favoring an El Niño SST pattern (see Supplementary Fig. 17).

So, we now ask: how does PI change if we compute it with a temperature profile and SSTs corrected to be comparable to observations? The answer is shown in Fig. 4d. First, we calculate the $\mathrm{PI}$ using the ensemble mean environmental variables (yellow): the resulting $\mathrm{PI}$ anomaly is very close to the the ensemble mean $\mathrm{PI}$ anomaly (red). This is a far from trivial fact, as the PI is highly nonlinear. Next we recalculate the PI using the corrected SST (yellow), then the corrected temperature profile (blue), and finally using both corrections together (green). The key point here is that corrected $\mathrm{PI}$ anomaly value is $-0.8 \mathrm{~m} / \mathrm{s}$ instead of the original $-1.5 \mathrm{~m} / \mathrm{s}$, which is much closer to the middle of the ensemble spread in non-volcano years (gray curves). Therefore, although PI is reduced following the volcanic eruptions in the CESM-LENS, this 
reduction is largely a consequence of the mismatch of the model and observations. We believe the same applies to many of the CMIP5 models, although we have not carried out the actual corrections.

Finally, we note that unlike the CMIP5 models, the CESM-LENS TCGI time-series show a decrease in following volcanic eruptions (Supplementary Fig. 13c, d), though this decrease in only clear in a few basins (Supplementary Fig. 18). This different response between CMIP5 and CESM-LENS is due to the fact dynamical response of the vertical shear is similar across the ensemble members in the CESM-LENS, increasing in some regions and decreasing in others (Supplementary Fig. 19), so that the CESMLENS reduction in TCGI is actually dominated by PI.

\section{CMIP5 models - storms}

Finally, to go beyond the indirect PI and TCGI metrics, we examine TC-like storms in the CMIP5 historical simulations. Although lowresolution climate models are capable of generating vortices with characteristics similar to those of TCs these storms are typically much weaker and larger than observed ones. ${ }^{23}$ These TC-like storms were detected and tracked in the CMIP5 models in Camargo, ${ }^{24}$ using the Camargo-Zebiak algorithm (see methods). Various aspects of these storms have been previously reported, as expected these TC-like storms do not intensify beyond tropical storm intensity. For the two models (MPI-ESM-LR and MRI-CGCM3) which simulate a reasonable global climatology and have produced multiple ensemble members, we have examined the distribution of the TC-like storms following volcanic eruptions: we find no robust reduction in NTC or ACE in either model (see Fig. 5 and Supplementary Table 5).

Finally, downscaling techniques can be used to generate synthetic storms from CMIP5 models' large-scale environmental

(a) NTC - MPI-ESM-LR
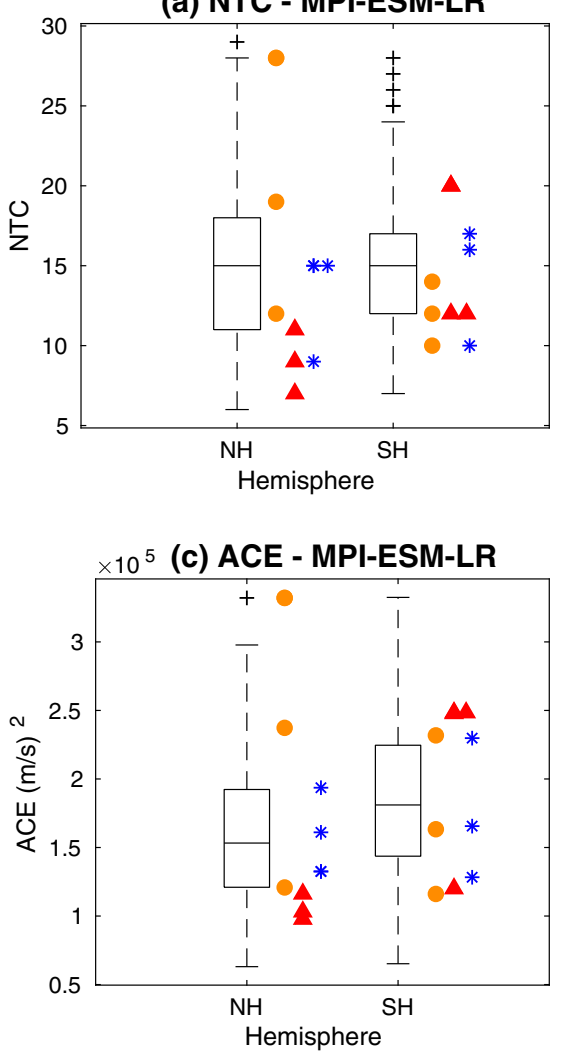

variables. ${ }^{25}$ One key advantage of this method is that it yields very large sets of storms, with characteristics similar to the observations. We here examine the synthetic storms generated by downscaling six CMIP5 models historical simulations as documented in Emanuel. ${ }^{26}$ In Fig. 6, we report both the climatological distribution of the synthetic storm metrics (box plots), and their values following the three large post-1950 volcanic eruptions (colored markers), using 600 synthetic storms generated per year globally. For each model we have calculated NTC, NTC13, NTC35, and ACE for all the synthetic storms, then normalized by the global frequency per year and model; the $\mathrm{NH}$ is shown in the left column, the $\mathrm{SH}$ in the right one.

Even with hundreds of storms at one's disposal (Fig. 6), we find no consistent reduction of TC activity following volcanic eruptions across all six models (see Supplementary Table 6). This lack of agreement among the models is particularly striking for Pinatubo, the largest and best observed recent low latitude eruption. This result is particularly significant because one of the inputs to the downscaling technique used here is PI, which appears to show a volcanic impact (see Fig. 3a, b). The key point is that even an unrealistic reduction in PI values does not lead to a significant lowlevel of global TC activity in the downscaled CMIP5 models.

\section{DISCUSSION}

We have examined the global response of TC activity to strong volcanic eruptions using observations, reanalysis, and models. We find no robust reduction of global TC activity in observations or reanalysis, with the exception of the North Atlantic, where the signal cannot be distinguished from an El Niño response. The CMIP5 and CESM-LENS large-ensemble historical simulations show a reduction of $\mathrm{PI}$ following volcanic eruptions, but this apparent

\section{(b) NTC - MRI-CGCM3}
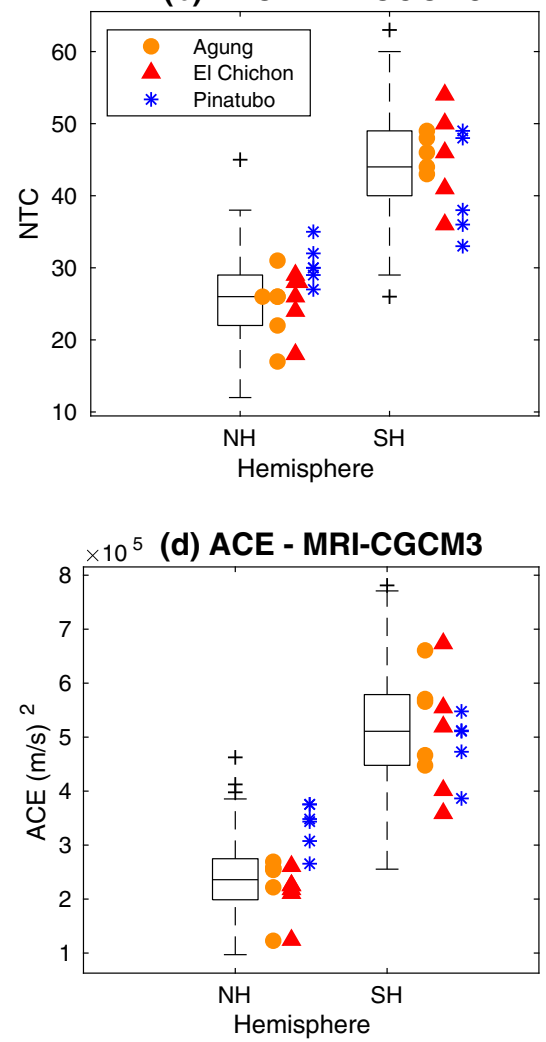

Fig. 5 Number of tropical cyclones (NTC), accumulated cyclone energy (ACE, in $\left.(\mathrm{m} / \mathrm{s})^{2}\right)$, and lifetime maximum intensity (LMI, in $\mathrm{m} / \mathrm{s}$ ) per year (southern hemisphere July-June) in the CMIP5 models MPI-ESM-LR ( 3 ensembles) and MRI-CGCM3 (5 ensembles) models in the historical simulation during the period 1950-2005 (southern hemisphere 1950/51-2004/5) and in the TC seasons following the volcano eruption 
(a) NTC

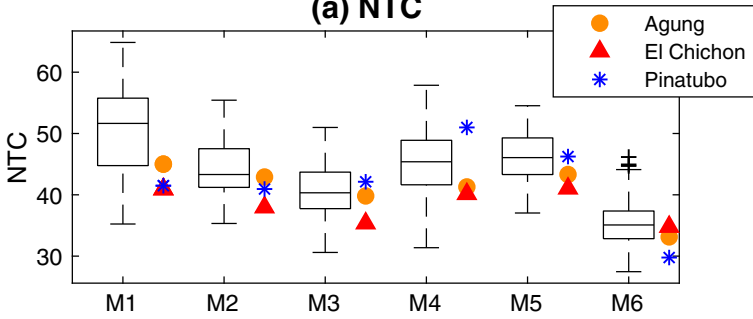

(c) TCs cat. 1-5

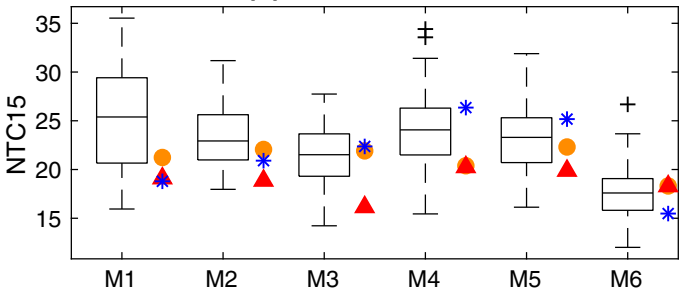

(e) TCs cat. 3-5

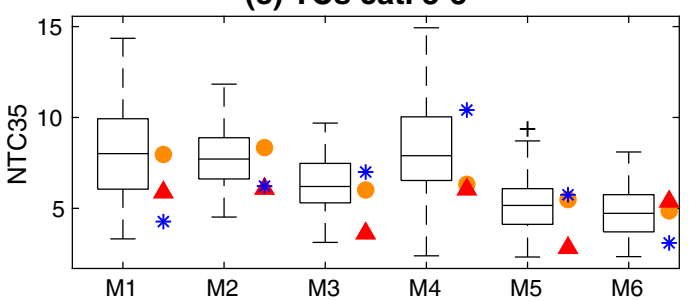

(g) ACE

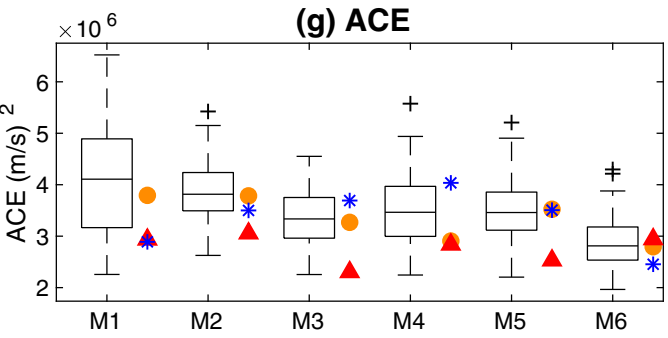

(i) LMI

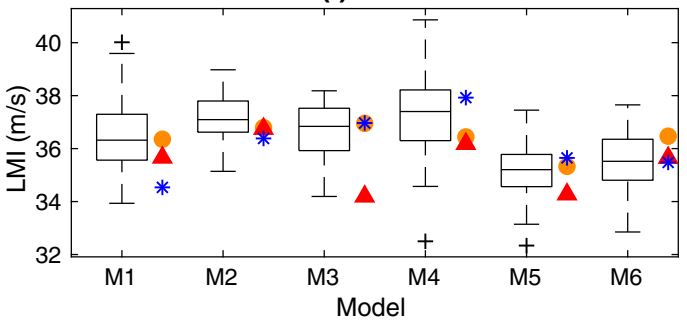

(b) NTC

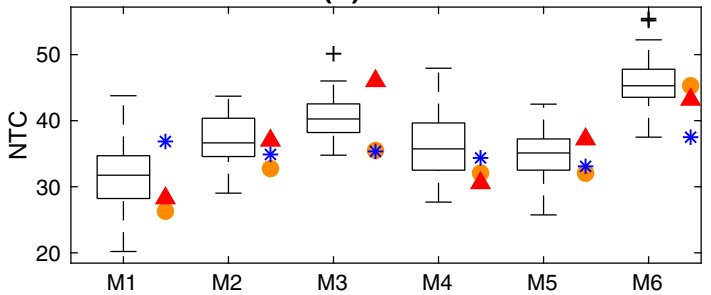

(d) TCs cat. 1-5

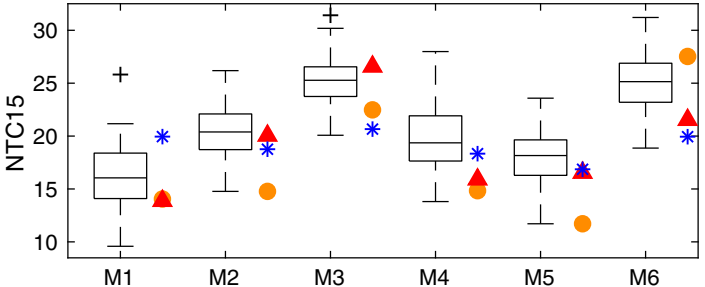

(f) TCs cat. 3-5

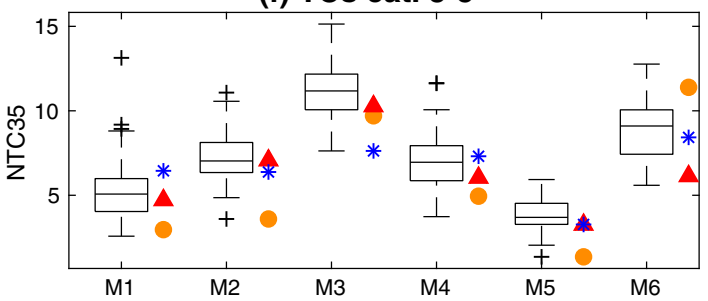

(h) ACE

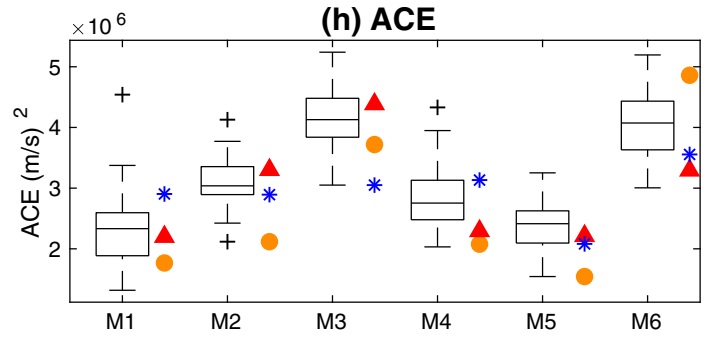

(j) LMI

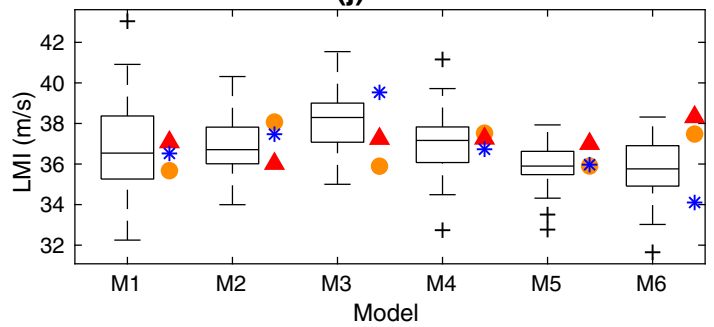

Fig. 6 The box plots (25th to 75th percentiles, central marks indicate the median) show the climatological distribution of NTC $\mathbf{a}$ and $\mathbf{b}$, NTC15 $\mathbf{c}$ and $\mathbf{d}, \mathrm{NTC} 35 \mathbf{e}$ and $\mathbf{f}$, ACE $\mathbf{g}$ and $\mathbf{h}$, and LMI $\mathbf{i}$ and $\mathbf{j}$ (see definition in the text) per year in the NH (left panels) and in July to June in SH (right panels) based on the downscaling of six CMIP5 models. NTC, NTC15, and NTC35 are counts, ACE is in (m/s) ${ }^{2}$ and LMI is in m/s). The whiskers show the range of the most extreme points not considered outliers, which are marked using + . Colored symbols show the values of these quantities for the first TC season after the volcanoes eruptions

reduction is likely unrealistic and overestimated due to model biases. More importantly, we find no volcanic impact in two different genesis indices, nor in TC-like storms, or in synthetic storms generated by several of these models.

Given the lack of robust evidence across a large number of datasets, and using very different methodologies, we are unable to validate earlier claims of a reduction of global TC activity following strong volcanic eruptions. It is not impossible that the lack of robust evidence reported here may stem, in part, from large biases in the current generation of climate models. It is also conceivable that particular eruptions may be able to affect TC activity, depending on the eruption timing, intensity, and volcano location. This impact could potentially vary by basin or even within a basin. If the TC response had opposite signs within a basin, for instance, as was the case of Saharan dust (e.g., ref. ${ }^{27}$ ), that would not lead to a statistically significant basin response. Or that the volcanic influence might be indirect: for instance, it has been suggested that volcanic eruptions may impart El Niño like features on SSTs, ${ }^{28}$ which might then affect TCs. For instance, Stevenson et al. $^{29}$ noticed that volcanic forcing can alter the 
climate by modifying the amplitude of climate modes, as well as by changing the teleconnections associated with those modes. Another possibility is that the volcanic eruptions modify the ITCZ location, which would also influence TC activity, as suggested in ref. $^{8}$. Recently ${ }^{30}$ showed in a modeling study that after Tamborastrength volcanic eruptions TC activity is modulated by the ITCZ response. However, in agreement with this study, there is no global reduction of TC activity even following those large volcanic eruptions. We will further explore these indirect effects of volcanic forcing on TC activity in a follow-up study.

\section{METHODS}

Data

To study tropical cyclones observed in the historical record, we employ the best-track datasets from the National Hurricane Center for the North Atlantic and eastern/central North Pacific, ${ }^{31}$ and from the Joint Typhoon Warning Center ${ }^{32}$ for the other regions. Owing to quality issues in the besttrack datasets, in particular the southern hemisphere $(\mathrm{SH}){ }^{33}$ we only consider the period 1961-2017 in the northern hemisphere (NH), and 1979-2017 in SH and the North Indian Ocean.

We explore TC activity via environmental variables. For robustness, we examine four different reanalysis datasets: the National Centers for Environmental Prediction - National Center for Atmospheric Research reanalysis (NCEP-NCAR, 1950-2016), ${ }^{34}$ the European Centre for MediumRange Weather Forecasts (ECMWF) reanalysis (ERA) - both the ERA-40 $(1958-2001)^{35}$ and ERA-Interim (ERA-Int, 1979-2016) ${ }^{36}$ - and the Japanese 55-year reanalysis (JRA-55, 1958-2014). ${ }^{37}$ We make use of the Extended Reconstructed Sea Surface Temperature (SST) version 3b (1854-2016). ${ }^{38}$ The climatological period for these is defined to be 1981-2010, with the exception of ERA-40, for which we use 1981-2000.

On the modeling side, similar environmental variables are taken from the output of historical simulations of 44 models participating in the Coupled Model Intercomparison Project 5 (CMIP5) (one ensemble member for each model for the period 1851-2005), and from 42 historical runs of the Community Earth System Model Large Ensemble (CESM-LENS) (over the period 1920-2005). ${ }^{40}$ The list of CMIP5 models analyzed here is given in Supplementary Table 1. The CMIP5 model output was also used to downscale synthetic storms, ${ }^{26}$ and to detect and track tropical cyclone-like storms. $^{24}$

\section{TC metrics}

As in most of the current literature, TCs are here defined as storms with maximum wind speed $\left(v_{m}\right)$ of least $17 \mathrm{~m} / \mathrm{s}$ during their lifetime, i.e., the number of TCs (hereafter NTCs) excludes tropical depressions. Besides NTC we consider the number of TCs that reach at least $33 \mathrm{~m} / \mathrm{s}$ and $50 \mathrm{~m} / \mathrm{s}$, i.e., categories $1-5$ and 3-5 in the Saffir-Simpson scale, called NTC15 and NTC35, respectively. The accumulated cyclone energy (ACE) is defined as $\sum v^{2}$ for all 6-hourly time-steps in which $v_{m}>17 \mathrm{~m} / \mathrm{s}$. ACE is an integrated metric that captures TC frequency, duration and intensity. The lifetime maximum intensity (LMI) ${ }^{41}$ is also analyzed; this metric is particularly useful for observations, as it is relatively insensitive to data uncertainty. The number of tropical storms (NTS; $17 \leq v_{m}<33 \mathrm{~m} / \mathrm{s}$ ) and categories 1-2 (NTC12; $33 \leq v_{m}<50 \mathrm{~m} / \mathrm{s}$ ) are shown in the supplement.

\section{Potential intensity}

The potential intensity $(\mathrm{PI})^{2}$ is defined as the theoretical maximum intensity that a TC can reach based on the local thermodynamic conditions. PI can be calculated from observed soundings, ${ }^{42}$ reanalyses ${ }^{43,44}$, and climate models, ${ }^{45}$ where it can be used as a proxy for TC intensity. PI has been shown to be closely related to the observed tropical cyclone intensity ${ }^{43,44}$ The standard formulation of $\mathrm{Pl}$, as given in Bister and Emanuel, ${ }^{46}$ is adopted here:

$$
\mathrm{PI}^{2}=\frac{C_{k}}{C_{d}} \frac{T_{s}}{T_{o}}\left(C A P E^{*}-C A P E\right)
$$

$\mathrm{PI}$ is an estimate of the maximum possible wind speed a TC might reach as a function of the surface temperature $T_{s}$, and outflow temperature $T_{o}$ (the temperature where a rising parcel is at the level of neutral buoyance, typically around the tropopause), the convective available potential energy (CAPE), and the CAPE of a saturated parcel (CAPE ${ }^{*}$, both calculated at the radius of maximum winds. $C_{k}$ and $C_{d}$ are the heat and drag coefficients.

\section{Genesis indices}

Tropical cyclone genesis indices are empirical proxies of TC frequency from the large-scale environment. An empirical tropical cyclone genesis index (TCGI) was constructed by Tippett et al. ${ }^{15}$ using a Poisson regression between observed climatological tropical cyclogenesis and large-scale climate variables from the ERA-Interim reanalyses. The specific TCGI formulation used here is:

$\mu=\exp \left(b+b_{\eta} \eta_{c l}+b_{S D} \mathrm{SD}+b_{P I} \mathrm{PI}+b_{V S} \mathrm{VS}+\log \cos \phi\right)$,

which is a function of the absolute low-level vorticity $\eta$ at $850 \mathrm{hPa}$ "clipped" (largest of $\eta \times 10^{5}$ and 3.7), vertical wind shear (VS, difference between the magnitude of the winds at 200 and $850 \mathrm{hPa}$ ), $\mathrm{PI}$ and saturation deficit (SD, difference between the specific and saturated humidity in the column), as discussed in Camargo et al., ${ }^{47}$ and in Daloz and Camargo ${ }^{48}$ for reanalyses. $\mu$ is the expected number of tropical cyclone genesis events per month, the $b$ 's are the coefficients of the regression, obtained by maximizing the likelihood. Menkes et al. ${ }^{49}$ showed that the TCGI performance is on par with or better than other genesis indices using various metrics. For robustness, we also compute the genesis potential index (GPI):3,13,16

$\mathrm{GPI}=\left|10^{5} \eta\right|^{3 / 2}\left(\frac{H}{50}\right)^{3}\left(\frac{\mathrm{PI}}{70}\right)^{3}(1+0.1 \mathrm{VS})^{-2}$,

which is a function of the absolute vorticity $\eta$, vertical shear, potential intensity and $600 \mathrm{hPa}$ relative humidity $(H)$.

\section{TC-like storms}

We examine the storms detected and tracked in a subset of the CMIP5 models, ${ }^{39}$ using the Camargo-Zebiak algorithm..$^{50} \mathrm{As}$ is typical of tracking algorithms, the Camargo-Zebiak algorithm finds features that have characteristics of TC-like storms in the output of climate models: local vorticity and surface winds maximum and sea level minimum, with a warm core. These features are then connected in time and space to make storm tracks. In order to take into account the horizontal resolution of models, we consider global thresholds for these environmental fields which are model dependent. The TC-like storms discussed here are from a subset of 14 CMIP5 previously analyzed. ${ }^{24}$ We restrict our analysis to the two models for which we tracked the storms and which have multiple ensemble members (Supplementary Table 1).

\section{Synthetic storms}

Finally, synthetic storms generated by downscaling the large-scale environmental fields of six CMIP5 models (Supplementary Table 1) using the Emanuel method ${ }^{25,26}$ are also included in our analysis. This technique first initiates storms by a random seeding in space and time, and these storms are then propagated using a track and an intensity model. The beta-advection track model is driven by the winds from the climate models. The intensity model is a high-resolution coupled oceanatmospheric model in angular momentum coordinates, which is integrated along each track. The intensity model determines the survival of each storm, with a majority of the seeds being discarded from their onset.

For all this data, we focus our analysis for the first TC season following strong eruptions, as the volcanic signal is likely to be strongest then. Our results do not change when we consider the 2nd TC season, or both seasons together. We examine the two hemispheres separately, as follows. Integrated anomalies over a "hemisphere" are computed in the TC prone regions in the tropics $\left(30^{\circ} \mathrm{S}-5^{\circ} \mathrm{S}, 5^{\circ} \mathrm{N}-30^{\circ} \mathrm{N}\right)$, with the Equatorial $\left(5^{\circ} \mathrm{S}-5^{\circ} \mathrm{N}\right)$, South East (west of $120^{\circ} \mathrm{W}$ ) Pacific and South Atlantic excluded, as there is rarely TC formation there. We use the Wilcoxon two-sided rank sum statistical test to ascertain whether the seasons following the volcanic eruptions are distinct from the climatological distribution. This is a nonparametric test for determining if two samples have the same medians.

\section{DATA AVAILABILITY}

The best-track datasets are available from the National Hurricane Center (nhc.noaa. gov)and the Joint Typhoon Warning Center (metoc.ndbc.noaa.gov/web/guest/jtwc/ best_tracks). The reanalysis datasets are publicly available from the European Centre for Medium-Range Weather Forecasts (www.ecmwf.int), the Japanese Meteorological Agency JRA-55 (jra.kishou.go.jp/JRA-55/index_en.html), and the National Oceanographic and Atmospheric Administration (www.ncdc.noaa.gov/data-access/modeldata/model-datasets/reanalysis) databases. CMIP5 data used for this project are publicly available from cmip.Inl.gov/cmip5/data_portal.html. The NCAR Large 
Ensemble data is also publicly available at www.cesm.ucar.edu/projects/communityprojects/LENS/. The SST data is available at www.ncdc.noaa.gov. The CMIP5 TC-like storm tracks are available by request from the corresponding author. The CMIP5 downscaled synthetic storm tracks are available for academic purposes by request from Kerry Emanuel via e-mail (emanuel@mit.edu).

\section{CODE AVAILABILITY}

The codes used to estimate the hurricane potential intensity are provided by Kerry Emanuel and can be downloaded at https://emanuel.mit.edu/products. The definitions used to calculate the genesis indices are given in Eqs. (2) and (3) of this manuscript.

\section{ACKNOWLEDGEMENTS}

S.J.C. thanks Adam Sobel and Michael Tippett (Columbia University) for comments on an earlier version of this manuscript. We thank Kerry Emanuel (MIT) for making the CMIP5 downscaled synthetic storms available for this study. We acknowledge the World Climate Research Programme's Working Group on Coupled Modelling, which is responsible for CMIP, and we thank the climate modeling groups (listed in Supplementary Table 1) for producing and making available their model output. For CMIP the U.S. Department of Energy's Program for Climate Model Diagnosis and Intercomparison provides coordinating support and led development of software infrastructure in partnership with the Global Organization for Earth System Science Portals. We also thank the CESM Large Ensemble Community Project and supercomputing resources for that project provided by NSF/CISL/Yellowstone. S.J.C. acknowledges funding from NOAA grants NA15OAR4310095 and NA16OAR4310079. L.M.P. is grateful for the continued support of the US National Science Foundation.

\section{AUTHOR CONTRIBUTIONS}

S.J.C. and L.M.P. designed the research and wrote of the manuscript. S.J.C. performed the data analysis.

\section{ADDITIONAL INFORMATION}

Supplementary Information accompanies the paper on the npj Climate and Atmospheric Science website (https://doi.org/10.1038/s41612-019-0070-z).

Competing interests: The authors declare no competing interests.

Publisher's note: Springer Nature remains neutral with regard to jurisdictional claims in published maps and institutional affiliations.

\section{REFERENCES}

1. Robock, A. Volcanic eruptions and climate. Rev. Geophys. 38, 191-219 (2000).

2. Emanuel, K. A. The maximum intensity of hurricanes. J. Atmos. Sci. 45, 1143-1155 (1988).

3. Emanuel, K. A. \& Nolan, D. S. Tropical cyclone activity and global climate. Bull. Am. Meteor. Soc. 85, 666-667 (2004).

4. Emanuel, K. Tropical cyclone activity downscaled from NOAA-CIRES reanalysis, 1908-1958. J. Adv. Model. Earth Syst. 2, 1 (2010).

5. Elsner, J. B. \& Kara, A. B. Hurricanes of the North Atlantic: climate and society. Chapter 10, 240-278 (Oxford University Press, New York, NY, 1999).

6. Evan, A. T. Atlantic hurricane activity following two major volcanic eruptions. J. Geophys. Res. 117, D06101 (2012).

7. Gray, W. M. Atlantic seasonal hurricane frequency. Part I: El-Niño and 30-MB quasi-biennial oscillation influences. Mon. Weather Rev. 112, 1649-1688 (1984).

8. Guevara-Murua, A., Hendy, E. J., Rust, A. C. \& Cashman, K. V. Consistent decrease in North Atlantic tropical cyclone frequency following major eruptions in the last three centuries. Geophys. Res. Lett. 43, 9425-9432 (2015).

9. Chiacchio, M. et al. On the links between meteorological variables, aerosols and global tropical cyclone frequency. J. Geophys. Res. 122, 802-822 (2017).

10. Korty, R., Camargo, S. J. \& Galewsky, J. Variations in tropical cyclone genesis factors in simulations of the Holocene Epoch. J. Clim. 25, 8196-8211 (2012).

11. Yan, Q., Zhang, Z. \& Wang, H. Divergent responses of tropical cyclone genesis factors to strong volcanic eruptions at different latitudes. Clim. Dyn. 50, 2121-2136 (2018).

12. Blake, E. S., Gibney, E. J., Mainelli, M., Franklin, J. L. \& Hammer, G. R. Tropical Cyclones of the Eastern North Pacific Basin, 1949-2006. (Historical Climatology Series 6-5, National Climatic Data Center and National Hurricane Center, National Oceanic and Atmospheric Administration, Ashville, NC, 2009).
13. Camargo, S. J., Emanuel, K. A. \& Sobel, A. H. Use of a genesis potential index to diagnose ENSO effects on tropical cyclone genesis. J. Clim. 20, 4819-4834 (2007).

14. Camargo, S. J. \& Sobel, A. H. Western North Pacific tropical cyclone intensity and ENSO. J. Clim. 18, 2996-3006 (2005).

15. Tippett, M. K., Camargo, S. J. \& Sobel, A. H. A Poisson regression index for tropical cyclone genesis and the role of large-scale vorticity in genesis. J. Clim. 24 2335-2357 (2011).

16. Camargo, S. J., Wheeler, M. C. \& Sobel, A. H. Diagnosis of the MJO modulation of tropical cyclogenesis using an empirical index. J. Atmos. Sci. 66, 3061-3074 (2009).

17. Driscoll, S., Bozzo, A., Gray, L. J., Robock, A. \& Stenchikov, G. Coupled Mode Intercomparison Project 5 (CMIP5) simulations of climate following volcanic eruptions. J. Geophys. Res. 117, D17105 (2012).

18. Sobel, A. H., Camargo, S. J., Previdi, M. \& Emanuel, K. A. Aerosols vs. greenhouse gas effects on tropical cyclone potential intensity. Bull. Am. Meteor. Soc. 99, 1517-1519 (2019).

19. Feichter, J. \& Roeckner, E. Nonlinear aspects of the climate response to greenhouse gas and aerosol forcing. J. Clim. 17, 2384-2398 (2004).

20. Lehner, F., Schurer, A. P., Hegerl, G. C., Deser, C. \& Frölicher, T. L. The importance of ENSO phase during volcanic eruptions for detection and attribution. Geophys. Res. Lett. 43, 2851-2858 (2016).

21. Stevenson, S., Otto-Bliesner, B., Fasullo, J. \& Brady, E. "El Niño like" hydroclimate responses to last millenium volcanic eruptions. J. Clim. 29, 2907-2921 (2016).

22. Randel, W. J., Garcia, R. R., Calvo, N. \& Marsh, D. ENSO influence on zonal mean temperature and ozone in the tropical lower stratosphere. Geophys. Res. Lett. 36 L15822 (2009).

23. Camargo, S. J. \& Wing, A. A. Tropical cyclones in climate models. WIREs Clim. Change 7, 211-237 (2016).

24. Camargo, S. J. Global and regional aspects of tropical cyclone activity in the CMIP5 models. J. Clim. 26, 9880-9902 (2013).

25. Emanuel, K., Ravela, S., Vivant, E. \& Risi, C. A statistical deterministic approach to hurricane risk assessment. Bull. Am. Meteor. Soc. 87, 299-314 (2006).

26. Emanuel, K. A. Downscaling CMIP5 climate models shows increased tropical cyclone activity over the 21st century. Proc. Natl Acad. Sci. USA 110, 12219-12224 (2013).

27. Pan, B. et al. Impacts of Saharan dust on Atlantic regional climate and implications for tropical cyclones. J. Clim. 31, 7621-7644 (2018).

28. Pausata, F. S. R., Chafik, L., Caballero, R. \& Battisti, D. S. Impacts of a high-latitude volcanic eruption on ENSO and AMOC. Proc. Natl Acad. Sci. USA 112 13784-13788 (2015).

29. Stevenson, S. et al. Climate variability, volcanic forcing, and last millenium hydroclimate extremes. J. Clim. 31, 4309-4327 (2018).

30. Pausata F. S. R. \& CamargoS. J.. Tropical cyclone activity affected by volcanically induced ITCZ shifts. Proc. Natl Acad. Sci. USA 116, 7732-7737, https://doi.org/ 10.1073/pnas.1900777116 (2019).

31. Landsea, C. W. \& Franklin, J. L. Atlantic hurricane database uncertainty and presentation of a new database format. Mon. Weather Rev. 141, 3576-3592 (2013).

32. Chu, J.-H., Sampson, C. R., Levine, A. S. \& Fukada, E. The Joint Typhoon Warning center tropical cyclone best-tracks, 1945-2000. Tech. Rep. NRL/MR/7540-02-16, Naval Research Laboratory (2002).

33. Kuleshov, Y. et al. Trends in torpical cyclones in the south indian ocean and south pacific ocean. J. Geophys. Res. 115, D01101 (2010).

34. Kistler, R. et al. The NCEP-NCAR 50-Year reanalysis: monthly means CD-ROM and documentation. Bull. Am. Meteor. Soc. 82, 247-267 (2001).

35. Uppala, S. M. et al. The ERA-40 re-analysis. Quart. J. R. Meteorol. Soc. 131 2961-3012 (2005).

36. Dee, D. P. et al. The ERA-Interim reanalysis: configuration and performance of the data assimilation system. Quart. J. R. Meteorol. Soc. 137, 553-597 (2011).

37. Kobayashi, S. et al. The JRA-55 reanalysis: general specifications and basic characteristics. J. Meteorol. Soc. Jpn 93, 5-48 (2015).

38. Smith, T. M., Reynolds, R. W., Peterson, T. C. \& Lawrimore, J. Improvements to NOAA's historical merged land - ocean surface temperature analysis (1880-2006). J. Clim. 21, 2283-2296 (2008).

39. Taylor, K. E., Stouffer, R. J. \& Meehl, G. A. An overview of CMIP5 and the experiment design. Bull. Am. Meteor. Soc. 93, 485-498 (2012).

40. Kay, J. E. et al. The Community Earth System Model (CESM) Large Ensemble Project: a community resource for studying climate change in the presence of internal climate variability. Bull. Am. Meteor. Soc. 96, 1333-1349 (2015).

41. Elsner, J. B., Kossin, J. P. \& Jagger, T. H. The increasing intensity of the strongest tropical cyclones. Nature 455, 92-95 (2008).

42. Wing, A. A., Emanuel, K. \& Solomon, S. On the factors affecting trends and variability in tropical cyclone potential intensity. Geophys. Res. Lett. 42, 8669-8677 (2015).

43. Wing, A. A., Sobel, A. H. \& Camargo, S. J. The relationship between the potential and actual intensities of tropical cyclones. Geophys. Res. Lett. 34, L08810 (2007).

44. Kossin, J. P. \& Camargo, S. J. Hurricane track variability and secular potential intensity trends. Clim. Change 9, 329-337 (2009). 
45. Sobel, A. H. et al. Human influence on tropical cyclone intensity. Science $\mathbf{3 5 3}$, 242-246 (2016).

46. Bister, M. \& Emanuel, K. A. Low frequency variability of tropical cyclone potential intensity. 1. Interannual to interdecadal variability. J. Geophys. Res. 107, 4801 (2002).

47. Camargo, S. J., Tippett, M. K., Sobel, A. H., Vecchi, G. A. \& Zhao, M. Testing the performance of tropical cyclone genesis indices in future climates using the HIRAM model. J. Clim. 27, 9171-9196 (2014).

48. Daloz, A. S. \& Camargo, S. J. Is the poleward migration of tropical cyclone maximum intensity associated with a poleward migration of tropical cyclone genesis? Clim. Dyn. 50, 705-715 (2018).

49. Menkes, C. E. et al. Comparison of tropical cyclonegenesis indices on seasonal to interannual timescales. Clim. Dyn. 38, 301-321 (2012).

50. Camargo, S. J. \& Zebiak, S. E. Improving the detection and tracking of tropical storms in atmospheric general circulation models. Weather Forecast. 17, 1152-1162 (2002)
Open Access This article is licensed under a Creative Commons Attribution 4.0 International License, which permits use, sharing, adaptation, distribution and reproduction in any medium or format, as long as you give appropriate credit to the original author(s) and the source, provide a link to the Creative Commons license, and indicate if changes were made. The images or other third party material in this article are included in the article's Creative Commons license, unless indicated otherwise in a credit line to the material. If material is not included in the article's Creative Commons license and your intended use is not permitted by statutory regulation or exceeds the permitted use, you will need to obtain permission directly from the copyright holder. To view a copy of this license, visit http://creativecommons. org/licenses/by/4.0/.

(c) The Author(s) 2019 